\title{
Pandemi ile İlgili Haberlerde Söylem Analizi: En Çok T1klanan Haber Sitelerinde Tematik Yapı Üzerine Bir İnceleme
}

Ramazan ÇELIK, Trakya Üniversitesi, Edirne Sosyal Bilimler MYO, Dr. Öğretim Üyesi, ramazancelik@trakya.edu.tr, (DD 0000-0002-6957-5297

$\ddot{O Z Z}$

Bir küresel salgina dönüşen Kovid-19 salgını ile birlikte online gazeteciliğe olan ilgide bir o kadar artış göstermiştir. Evde geçirilen karantina süreci internet tabanlı olan yeni iletişim teknolojilerinin altın çağının başlaması anlamına gelmiştir. Artık fiziksel olan ile dijital olanın birleştirildiği dönem olan "fijital" süreci yaşanmaktadır. Birçok bilimsel veri ve görüş "yeni normal" denilen bu dönemin kahıılığını tartışır hale getirmiştir. Bu çalı̧ma online gazetecilik ortamında pandemi ile ilgili haberlerde "yeni normal" ve "fijital" kavramlar bağlamında haberin yeniden üretiminin mümkün olup olmadığı sorunsalına odaklanmaktadır. Bu durum verilen haberin haber değerinden, içeriğine kadar birçok başlı̆̆ının yeniden gözden geçirilmesinin önemli olduğunu göstermektedir. Bu nedenle pandemi sürecinde günlük vakalarm ele alındığı haberlerde zamanla havada uçuşan rakamlardan başkaca bir şey verilmediği görülmektedir. Bu da zamanla bilginin anlamsızlaşması, griftleşmesi ve haberin amacından uzaklaşıldı̆̆ı̆ı göstermektedir. Bir haberin hakl bilgilendirmesinden çok sadece günlük vaka sayılarmın verildiğ kaliplara gömülmesi, habere olan ilginin de zamanla azalmasına sebep olmaktadır. Bu çalışma ile günlük en çok tıklanan haber sitelerinde pandemi ile ilgili haberlerin nasıl verildĭği, Van Dijk'ın söylem çözümlemesi modelinde yer alan makro yap üzerinden değerlendirilmektedir.

Anahtar : Söylem Analizi, Pandemi, Fijital, Online Gazetecilik, Haber

Kelimeler

\section{Discourse Analysis in Pandemic News: A Research on The Thematic Structure in The Most Clicked News Sites}

ABSTRACT

With the Covid-19 epidemic that turned into a global epidemic, interest in online journalism has increased as much. The quarantine process spent at home has meant the beginning of the golden age of new internet-based communication technologies. Now, there is the "phygital" process, which is the period in which the physical and the digital are combined. Many scientific data and opinions have brought into question the permanence of this period, which is called the "new normal". This study focuses on the question of whether it's possible to reproduce the news in the context 
of the concepts of "new normal" and "phygital" in the news about pandemic in the online journalism environment. This situation shows that it is important to review many headlines of the news from news value to content. For that reason, it's seen that in the news in which daily cases are dealt with during the pandemic process, nothing other than the numbers flying in the air over time. This shows that over time information becomes meaningless, intricacy and the purpose of the news is lost. The fact that a news is embedded in patterns where only the daily number of cases are given rather than justified information causes the interest in the news to decrease over time. With this study, how the news about the pandemic is given on the daily most clicked news sites is evaluated through the macro structure in Van Dijk's discourse analysis model.

Keywords : $\quad$ Discourse Analysis, Pandemic, Phygital, Online Journalism, News

\section{EXTENDED ABSTRACT}

\section{Aim and Scope}

The aim of the study is to analyze what kind of discourse the most read news websites in Turkey construct while reporting the news about the pandemic. The news on the news websites of Hürriyet, Sabah and Sözcü newspapers, which were the most clicked and ranked in the top four, were evaluated within the scope of the study.

This study focuses on the question of whether it's possible to reproduce the news in the context of the concepts of "new normal" and "phygital" in the news about pandemic in the online journalism environment. This situation shows that it is important to review many headlines of the news from news value to content. With this study, how the news about the pandemic is given on the daily most clicked news sites is evaluated through the macro structure in Dijk's discourse analysis model.

\section{Methods}

The method of the study consists of evaluating the news about the pandemic through the macro structure in discourse analysis using Teun Van Dijk's Discourse Analysis model.

\section{Findings}

The findings obtained in this study in which the discourse addressed in internet news is evaluated through the macro structure in Dijk's discourse analysis; shows that online journalism has serious problems in terms of journalism news writing principles and techniques. 
Compared to the news in the mass media, it is seen that the news published in the online field are written unnecessarily long in the cyberspace. In the examinations, many spelling mistakes were found besides long sentences.

While there are many unnecessary and lengthy details in the use of headlines in the Hürriyet and Sabah news, it has been determined that Sözcü news is given more simply, and more attention is paid to the structure or construction of the sentence.

While Hürriyet and Sabah tended to provide general information about the pandemic with a very long and gathering news logic, Sözcü news site preferred the simple and plain language that it used in the headlines, mostly over the events of that day.

The main hero in both headlines and news entries/spots was Health Minister Fahrettin Koca. Due to the fact that it is almost the only source of news for the pandemic every day, Minister Koca is mentioned as the main hero or the subject of the news in all news texts within the scope of the research.

Another important subject of the thematic structure is the photographs, infographics or tables used in the news. In the study, the photograph of Minister Koca was used in all samples in the early days of the pandemic. Afterwards, there was a daily corona table announced by the ministry every day. Finally, with the onset of the second wave in the pandemic, it is seen that the images of patients, health workers, patients who have had an injection, crowded people related to public transportation are used more intensely.

\section{Conclusion}

The problems related to the construction of the news in the online journalism environment were evaluated in the axis of the news about the pandemic. This study detects that many information, news, on the axis of the "phygital" concept, which emerges from the merger of the real and the digital, becomes obscured or diverges from its meaning. During the pandemic process, it has been determined that the information conveyed in the news where daily cases are dealt with is nothing but numbers flying in the air over time. This situation means that the news text constructions, which have become more meaningless over time, increase in time. For this reason, it is necessary to carefully evaluate the studies handled with discourse analysis and to spread the rules and philosophy of journalism in online environments. In addition to the increase in such studies, it will be important to take structural steps regarding online journalism.

\section{GİRIŞ}

Haber söylem ve analizi çerçevesinde birçok araştırma söylemin gücü ve etkinliği üzerine odaklanarak, ardalan bilgisinde olaylar ile ilgili anlamlı verilere ulaşmayı hedeflemektedir. Geleneksel medya süreçlerinde kitle iletişim araçları üzerinden gerçekleşen 


\section{AJIT-e Bilişim Teknolojileri Online Dergisi \\ Academic Journal of Information Tecnology}

2021 Spring/Bahar - Cilt/Vol: 12 - Sayr/Issue: 45

doi) 10.5824/ajite.2021.02.003.x

veri akışında söylem analizleri yapılmakta iken günümüzde bu çalışma alanının kapsamı genişlemiş, online mecralarda da söylem analizleri çalışmaları yapılmaya başlanmıştır.

Küresel bir salgın olan ve milyonlarca insanın ölüm ve hastalanmasına neden olan Kovid-19 pandemisi* evlerde zorunlu-gönüllü karantinalara girilmesi nedeni ile bireylerin yaşam standartlarında da değişimlere ve "yeni normal" de denilen dönemlerin yaşanmasına sebep olmaktadır. Bu nedenle günlük yaşamda yaşanan değişim ve dönüşüm bireylerin yeni iletişim ortam ve teknolojilerini kullanma alışkanlıklarını da köklü olarak değiştirmiştir. Bu değişim eğitimden iş yaşamına kadar çok geniş yelpazede standartların dış yaşamdan ev ortamına geçişini sağlamış ve bireylerin online eğitim ortamlarında, online iş ortamlarında, sosyal paylaşım ağlarında, sanal gerçeklik ya da arttırılmış gerçeklik uygulamalarında kendini yeniden var etmesine olanak sağlamıştır.

Bu durum fiziksel olan ile sanal ya da dijital olanın birleşmesi sonucu "fijital" adı verilen kavramın doğmasına, bu kavramın hayatımıza dahil olmasına sebep olmuştur. Artık fiziksel olan ile sanal olan arasında net bir geçirgenlikten ziyade griftleşmiş bir durumun varlığının görülmesi karmaşıklığın daha da artacağı endişesini doğurmaktadır. Birçok bilimsel çalışma ekseninde yeni iletişim ortamlarında yer alan veri akışının içeriğinin de sorgulanması bu karmaşıklığın netleştirilmesi çabasına yönelik değerli bir adım olacaktır. Bu nedenle bu çalışma haber sitelerinde yer alan haberlerin söylem analizi çerçevesinde değerlendirilmesi ile bu ortamda yaşanan belirsizlik ve karmaşıkların tespiti açısından önem taşımaktadır.

Çalışmada Türkiye'de günlük en çok tıklanma oranlarına sahip olan üç önemli haber sitesinde (Hürriyet, Sabah, Sözcü) yer alan pandemi ile ilgili haberlerin söylem analizi yapılmaktadır. Çalışma kapsamında T. V. Dijk'in söylem analizi modeli üzerinden haberlerin makro yapısı değerlendirilmektedir.

\section{SÖYLEM VE SÖYLEM ANALİŻ}

Dilbilimde, cümlelerin, tümcelerin ve kelimelerin genel tanımlarının yanında farklı anlam ve içeriklerinin de olacağı unutulmamalıdır. Zira bir "verilen" bir de "verilmek istenen" vardır. Mutlu'ya (2012, s.280) göre örneğin söylem bir sözü (ki bunlar bir şarkı sözü, şiir, ya da mülakat olabilir) oluşturan herhangi bir söz dizisini dile getirebilir.

Söylem Benveniste'ye göre (1971) bir konuşmacı ile dinleyiciyi ve konuşmacıda dinleyiciyi bir şekilde etkileme niyetini varsayan her türden ifade, Foucalt'ya göre (1972)

\footnotetext{
" Küresel salgın anlamına gelen "pandemi" kelimesi yoğun kullanılması nedeni ile artık bilinen bir kavramdır. Bu nedenle çalışmada Koronavirüs salgını pandemi olarak ifade edilmektedir.
} 
söylem bir ibareler dizisi olmaktan öte bir şey, Fiske'ye göre (1988) ise ortak sayıltılarla bir araya getirilmiş, bütünleşikleştirilmiş bir dil kullanım alanıdır (Akt., Mutlu, 2012, s.280).

Söylemlerin "verilmek istenen" üzerinden söylenemeyen ya da düşünülemeyen bazı şeyler üzerinden inşa edilmesi, söylemlerin aynı zamanda bilimsel ve ideolojik yönden de ayrılması gerektiğini göstermektedir. Althusser, bilimsel söylem ile ideolojik söylemi ayırt eder ve bilimsel bir söylemin gerekli bilgi sonucunu vermek ve konusuna uygun felsefi olarak temizlenmiş "kuramsal" kavramlar dizisini oluşturmak zorunda olduğunu, ideolojik söylemin ise "kapalı bir bilme uzamında" iş gördüğünü belirtir (Althusser ve Balibar 1970'ten Akt., Mutlu, 2012, s.281).

Benveniste, Foucault, Fiske ve Althusser'in söylem üzerine literatüre katkısına bakıldığında daha çok söylenen değil söylenmek istenene odaklandıkları görülmektedir.

Söylem analizi çalışmalarında hatırı sayılır yeri olan Teun Van Dijk (1983) ise dil çalışmalarında, ağırlığı tek tek sözcüklerin, deyimlerin ya da cümlelerin incelenmesinden dilin fiili kullanım biçimlerinin yapılarının ve işlevlerinin çözümlenmesine (Akt., Mutlu, 2012, s.281-282) kadar geniş bir yelpazede konunun ele alınması gerektiğini ifade eder.

Wood ve Kroger (2000), söylem analizi ile ilgili olarak yöntembilim ve kavramsal olan unsurların meydana getirdiği sosyal hayata dair ne varsa bunların bir perspektif olarak görülmesi gerektiğine vurgu yaparlar. Söylem üzerine düşünmenin yani teorik ve sosyolojiye ilişkin olarak ise meta-teorik öğeler üzerinden söylemi verileştirme (data) üzerinden ele alırlar ederler. Bu analiz yöntemi sadece geleneksel metodolojilere bir alternatif olmayıp, aynı zamanda bu metodolojilerin içine sokulmuş bakış açılarına karşı bir alternatiftir (Wood ve Kroger 2000'den Akt., Çelik ve Ekşi, 2013, s.104-105). Söylem analizi kuramsal bakış açısı olarak detaylı ve nitel yaklaşımlara doğru anlamlı ve bilimsel geçişi sağlayan bir yöntemdir.

Sosyal psikolojik metodolojide sosyal dünyanın kasıtlı ikna girişimleri ve meşrulaştırma gibi durumlarında söylem analizine odaklanılır ve dil öğeleri kullanılır. Dil öğeleri görüntüler, çelişkili siteler, üretilen paradokslar ve tartışmalı veriler üzerine odaklanır ve durumu dilsel organizasyon çerçevesinde açıklar (Elliott, 1996, s.65). Elliott'ın da belirttiği gibi söylem analizi son yıllarda sosyal psikolojik metodolojinin önemli bir çalışma alanıdır. Bu nedenle nitel araştırma yöntemi olarak söylemin "anlamlılık"a odaklanması bu çalışma yöntemini daha da etkili kılmaktadır.

Yeni disiplinler arası söylem çalışmaları, 1960'ların ortalarından beri beşeri ve sosyal bilimlerin çoğunda yapılmaya başlamıştır. Bu gelişme aşağı yukarı diğer birkaç yeni disiplinler arası (pragmatik, dilbilim, gösterge bilim, sosyalpsikoloji, psikodilbilim vb.) özgürleşmeyle aynı zamanda ve yakından ilişkilidir. Yine de başlangıçta "söylem analizi", tıpkı göstergebilim gibi, çeşitli dallardan belirli kavramlara dayanıyordu. Böylelikle yapısal ve 
işlevsel dilbilim, sonraki yeni gelişmelerden esinlenmiştir ve etkilenmiştir (Teun A. van Dijk, 2009, s.191).

Sosyal ve beşeri bilimlerde önemli bir disiplin haline gelen söylem analizi çalışmaları Van Dijk'ın da belirttiği gibi yapısal ve işlevsel dil bilim alanında etkisini arttırmış ve yapılan analizler sonrası anlamlı verilerin elde edilmesi mümkün hale gelmiştir. Alan yazını oldukça geniş olan söylem analizi çalışmalarında öne çıkan Barker ve Galasinski, D. (2001), Elliott, R. (1996), Parker (1990-2002), Potter ve Wetherell (1987), Wodak ve Meyer (2002), Wood ve Kroker (2000) ve Van Dijk (2003-2009) gibi isimler konu ile ilgili önemli araştırma ve değerlendirmeler yapmışlardır.

\subsection{Haberlerde Söylem Analizi}

Söylem analizi, söylem ve iletişim çalışmalarının örtüştüğü alanlardan birisidir. İletişim araştırmalarındaki çalışmalar, sosyal olarak konumlandırılmış metin veya konuşma biçimleri olarak incelenmelidir. Bu yeni odaklanmada özellikle basında çıkan haber çalışmalarında uygulanmıştır (Teun A. van Dijk, 2009, s.191).

Güncel haber araştırmalarının ideoloji çalışmasıyla bazı paralellikleri vardır: Haberler başlangıçta haber toplama gibi haberlerin sosyal boyutlarına yönelikti. Rutinler ve gazetecilik etkileşimleri ile gazetelerin organizasyonu bilişsel ve söylemsel yaklaşımlar üzerinden ele alınmıyordu. İlk sistematik söylemsel ve bilişsel yaklaşımlarda yapılan haber yapıları, haber üretimi ve haber anlayışı 1980'lere kadar ortaya çıkmadı.

$\mathrm{Bu}$ nedenle, söylem yapısı ve söylem işleme üzerine yaptığı önceki çalışmalarına dayanarak, Van Dijk bir haber şeması teorisi içeren multidisipliner bir haber teorisi önerdi. Bu teoriye göre bir tür ve sosyal uygulama olarak geleneksel haber söylemi kategorileri tarafından tanımlanan, özet (başlık, giriş cümlesi), yeni etkinlikler, önceki etkinlikler, bağlam, yorum ve ilgili kategoriler basında yer alan haberlerin (makro düzeyde) konularını küresel olarak organize eden (Teun A. van Dijk, 2009, s.194) bir boyut kazand.

Van Dijk'a (2009, s.194-195) göre "haber hikâyeleri", "hikayeler" gibi görünse de sohbette anlatılan günlük hikayelerle aynı şematik (üstyap1) organizasyonlara sahip değillerdir. Günlük hikayeler aşağı yukarı kronolojik bir özellik taşırken, haber metinleri ise alaka, önem ve yenilik gibi diğer birçok ilkeye göre düzenlenir. Burada ilk dikkati çeken ve en önemli bilgi olan haberin başlı̆̆ıdır. Söylem, özet (haberin giriş cümlesi) pek çok metinde olduğu gibi verilir ve haber metni en önemli bilgiler ilk sırada, ardından daha az önemliye doğru (ters piramit yöntemi) bilgiler ile verilir. Bu çalışma Van Dijk'ın belirttiği gibi haber metninde en önemliden önemsize doğru verilen bilgi akışı nedeni ile söylem analizi yapılırken pandemi ile ilgili verilen haberlerin başlığına ve giriş cümlesine odaklanmanın daha doğru 
veriler elde etmede önemli etken olduğu düşünülmektedir. Bu bağlamda Van Dijk'ın söylem çözümlemesi modeline göre söylem analizi yapılacaktır.

\section{2. İnternet Haberlerinde Söylem Analizi}

Yeni iletişim ortam ve teknolojilerinin de etkisi ile söylem analizi çalışmaları geleneksel gazetecilik çalışmaları ekseninden çıkıp online gazetecilik ekseninde de değerlendirilmeye başlamıştır. Özellikle internet ortamında veri elde etmenin daha kolay olması ve zaman kazandırması bu yönüyle söylem analizi çalışmalarının da daha yoğun yapılması sonucunu doğurmaktadır.

İnternet haberciliği ya da online gazetecilik diye de adlandırdığımız yeni haber mecrası birçok anlamda haber üretimini yoğun bir şekilde zaman şartına bağlı kalmadan her an her yerde verme imkanına kavuşmuştur. Ekonomik ve politik yönüyle güçlü bir konum elde eden ve gün geçtikçe de yeni iletişim ortam ve araçlarının daha çok kullanılması ile internet gazeteciliğini hem gazeteciliğin geleceği adına hem de yeni bir gazetecilik anlayışının da ortaya çımasını adına daha da önemli hale getirmektedir. Bu nedenle bu mecralarda üretilen haber metni ve öğeleri de gözden geçirilmelidir ki gerçek anlamda bu değişim ve dönüşümün dinamikleri belirlenebilsin.

İnternet ortamında verilen haberin kullanım şekli durumu daha kapsamlı ele alma gerekliliğini ortaya çıarmaktadır. Geleneksel medya üzerinden dinleyici, okuyucu, izleyici gibi tanımlar üzerinden haber tüketimi sağlanırken, yeni iletişim ortamlarında multi-media (çoklu ortam) ile görsel, yazı, ses, video vb. öğelerin tamamını birbirine entegre görebilir ve tüketim esnasında ise sadece "kullanıcı" olabilirsiniz. Yani temel eğilim seyretmek, dinlemek ve okumaktan ziyade "interneti kullanmaktan ibarettir".

Kullanım noktasında yaşanan bu değişim haberin içeriğinin de değiştiğini göstermektedir. Geleneksel medya ve yeni medya ortamlarında yer alan haberlere bakıldığında ele alınan haber dilinden kullanılan görsele kadar birçok şeyinde farklılaştığı görülmektedir.

Söylem analizi yapılırken, haberde kullanılan yüklemden, cümle yapısına, başlıkların sıralanışından kullanılan görsellere kadar haber inşasında öne çıkan bütün öğelerin ayrıntılı olarak incelenmesi ve analiz edilmesi esastır. Türkçe cümle yapısındaki değişim, haber girişlerindeki tematik yapının değişim göstermesi (ana olayın teması ve içeriği, gazetenin ideolojik bakış açısı vb.), kullanıcının dikkatini çekmek için kullanılan infografikler, fotoğraflar, fotoğraf altı yazılar gibi birçok değişken internet haberlerinde tematik yapının yeniden gözden geçirilmesi gerektiğini göstermektedir. Bu nedenle bu çalışma daha çok haber dinamiklerinin tematik boyutu ile ilgilenmektedir. 


\section{PANDEMİ İLE BİRLİKTE DEĞİŞEN ÇEHRE}

Küresel bir salgın olarak hayatımızın her evresini değiştiren "koronavirüs pandemisi" yeni iletişim ortam ve teknolojilerinin kullanım oranı ve çeşitliliğini de değiştirmiştir. Eğitimden kültür sanata, oyundan tüketim anlayışımıza kadar artık "yeni normal" denilen bir dönemde yaşamaktayız. Bu nedenle bu kısımda kısaca bu değişimlerden bahsetmek yerinde olacaktır.

Yapılan birçok araştırmaya göre dijital ortamları kullanma oranımız çok hızlı bir yükseliş ile kat be kat artış göstermektedir. Özellikle pandeminin etkisi ile milyonları ilgilendiren eğitim öğretimin uzaktan yapılması bu oranın çok hızlı artmasını sağlayan en önemli etkenlerden bir tanesidir. Bulaş riskini ortadan kaldırmak için restoranların kapatılmasıyla online yiyecek ve içecek sektörüne yönelmek ya da kültür ve sanat ile ilgili online müze gezmekten online opera seyretmeye kadar birçok yaşamsal alan internet ağları üzerinden yaşam bulmaktadır.

$\mathrm{Bu}$ durum ise "gerçek" olan ile "yapay gerçeklik" arasında sıkışmış kullanıcı profillerinin sayısının güç geçtikte çok hızlı artması ve bazı sorunların da ortaya çıkmasına neden olmaktadır. Kullanıcı rolünde olan bir nevi tüketici de olan bireylerin bu yaşanan değişim ve dönüşümdeki konumunu belirlemek bu yönüyle çalışma adına önemli bir göstergedir.

Pandeminin yayılarak devam etmesi birçok sektöründe online mecrada daha çok aktif hale gelmesine neden olmuştur. Örnek vermek gerekirse yüz yüze satış merkezli olan birçok mağaza, kafe, restaurant geleneksel satış yönteminden uzaklaşıp online mecralara yönelmiştir. Bu bağlamda da fiziksel dünya ile dijital dünyanın kesişiminden doğan "Fijital" (Phygital $=$ Physical + Digital) (Çalışkan, 2020, s.1) kavramı literatüre girmiştir. Özelikle pandeminin bulaş riskinin olması hayatımızda diğer insanlar ile sıfır temasın daha güvenli olması sonucunu doğurdu. Giyim markalarının elektronik ayna uygulamaları, QR kod uygulamaları, temassız kredi kartı ödemeleri, sıfır temas yöntemi ile yiyecek içecek ya da kargo teslimi gibi fiziksel olanı tamamen devre dişı bırakan uygulamaların hayatımıza girmesine sebep oldu.

Pandemi özelinde ikinci dalganın yaşanmasına dair korku ve endişe ortamı ekonomik çarkların da günümüz koşullarında sektörlerin değişiminin de artarak devam ettiğini göstermekte özellikle online mecralarda yapılan harcamaların giderek arttığını ve kartlı harcamalarda oranın giderek yükseldiğini göstermektedir. Resmi verilere göre (Çalışkan, 2020, s.1-3) 2020 yılının ilk yarısında internetten kartlı ödeme oranı dörtte birlik bir artışla toplamda 107 milyar TL oldu. Ayrıca 2019'un ilk 6 ayında yaklaşık yüzde 18 olan internetten kredi ya da banka kartı ile yapılan ödemelerin toplam kartlı ödemelerdeki payı 3 puan artışla 
yüzde 21'e çıktı. Bu artış ile ilgili yönelim dikkate alındığında 2020 yılı sonunda da her 4 TL kartlı ödemenin 1 TL'si yani 4'te 1'inin internetten yapıldığı ve bu trendin çok hızlı bir şekilde arttığı görülmektedir. We Are Social (2020) raporundaki verilere göre 16-64 yaş arasındaki kullanıcıların bu trende uydukları görülmektedir. Son 30 günlük e-ticaret aktivitelerine bakıldığında internet kullanıcılarının yüzde 80'inin online ürün araması yapmakta olduğu ve yine yüzde 90'ının ise online mağaza ziyaretleri gerçekleştirmekte olduğu görülmektedir.

Tüketim adına bu tarz eğilimler söz konusu iken, pandemi haberlerine yönelik ise bakış açısında bir değişimin olduğu ifade edilmektedir. Yapılan araştırmalar, tüketici konumunda olan kullanıcının (birey) pandemide ikinci dalga yaşanmasına, vaka ve ölümlerde rekorların kırılmasına rağmen bu tarz haberlere olan ilgisinin azalmış olduğunu göstermektedir. Amerika merkezli ve 2016 yılında kurulan bir haber sitesi olan Axios ile sosyal medya ölçüm platformu olan Newswhip önemli bir araştırma yapmıştır. Yapılan araştırmanın sonucuna (Axios, 2020) göre, salgında ikinci dalganın büyüdüğü, ancak salgın ile ilgili rekorlar kırılmasına rağmen okurların ve izleyicilerin ilk dalgaya nazaran pandemi ile ilgili haberlere karşı ilgi ve dikkatin yoğun olmadığı tespit edilmiştir. Bu tarz bilimsel veriler çalışmamızda pandemi ile ilgili haberleri söylem analizinde tematik olarak değerlendirmenin bir kez daha ne kadar önemli olduğunu göstermektedir.

\section{AMAÇ VE YÖNTEM}

Çalışmanın amacı Türkiye'de en çok okunan gazete haber sitelerinin pandemi ile ilgili haberleri verirken nasıl bir söylem inşa ettiklerinin analizini yapmaktır. Araştırmanın yöntemi Teun Van Dijk'ın Söylem Çözümlemesi modeli kullanılarak pandemi ile ilgili haberlerin söylem analizinde makro yapı üzerinden değerlendirilmesinden ibarettir.

Tablo 1: Teun Van Dijk'ın Söylem Çözümlemesinde Makro Yapı

\begin{tabular}{|ll|}
\hline \multicolumn{3}{|c|}{ Söylem Analizinde Makro Yapı } \\
\hline 1) & Tematik Yapı \\
a) & Başlık \\
b) & Haber Girişi: Spotlar/Haber girişleri (spot \\
yoksa) & \\
c) & Fotoğraf \\
2) & Semantik Yapı \\
a) & Durum: Ana olayın girişi/Sonuçlar/ Ardalan \\
bilgisi/Bağlam bilgisi \\
b) & Yorum: Haber kaynakları/Haber yorumları \\
\hline
\end{tabular}


İnternet ve dijital değişimleri takip eden, inceleyen ve analiz eden Webrazzi (2020) verilerine göre gazetesi olan haber sitelerinden en çok tıklanan ve ilk dört sırada yer alan Hürriyet, Sabah ve Sözcü gazetelerinin haber sitelerinde yer alan haberler araştırma kapsamında değerlendirmeye alınmıştır.

Araştırmada Türkiye'de resmi verilere göre ortaya çıkan ilk vakanın olduğu tarih olan 11 Mart 2020, pandeminin ilk dalgasının zirve rakamlarına ulaşıldığı 11 Nisan 2020 ve pozitif hastaların tamamının ilan edildiği gün olan 25 Kasım 2020 tarihlerinde verilen haberler makro yapı kapsamında değerlendirilmektedir.

Yöntem olarak Teun Van Dijk'ın söylem çözümlemesinde makro yapı üzerinden tematik yapı dikkate alınarak pandemi ile ilgili verilen haberlerin başlıkları, giriş cümleleri (spot ve haber girişleri) ve haberde kullanılan fotoğraf ve görselleri analiz edilmektedir.

\subsection{Bulgular ve Yorumlar}

\subsection{Makro Yapıda Tematik Çözümleme}

\subsubsection{Başlıklar}

Pandemi ile ilgili haberlerde verilen başlıklar ilk vakanın görüldüğü 11 Mart 2020, pandeminin ilk dalgasının zirve rakamlarına ulaşıldığ 11 Nisan 2020 ve pozitif hastaların tamamının ilan edildiği gün olan 25 Kasım 2020 tarihlerini kapsamaktadır.

Tablo 2: 11 Mart 2020 İlk Vakanın Görüldüğü Gün

\begin{tabular}{|l|l|l|}
\hline \multicolumn{1}{|c|}{ Hürriyet Haber Sitesi } & \multicolumn{1}{|c|}{ Sabah Haber Sitesi } & \multicolumn{1}{c|}{ Sözcü Haber Sitesi } \\
\hline Bakan Koca: Bir vatandaşımızın & Sağlık Bakanı Koca'dan son & Sağlık Bakanı \\
test sonucu pozitif çıtı & dakika koronavirüs açıklama sı!! & Türkiye'deki ilk Corona virüsü \\
& Türkiye'de ilk kez corona & vakasını duyurdu! \\
& virüsü tespit edildi... & \\
\hline
\end{tabular}

Tablo 3: 11 Nisan 2020 İlk Dalganın Zirve Yaptığı Gün

\begin{tabular}{|l|l|l|}
\hline \multicolumn{1}{|c|}{ Hürriyet Haber Sitesi } & \multicolumn{1}{|c|}{ Sabah Haber Sitesi } & \multicolumn{1}{|c|}{ Sözcü Haber Sitesi } \\
\hline Sağlık Bakanlığı corona virüsüu & Türkiye'deki son corona & Sondakika haberi: Bakan \\
il il tablosu 11 Nisan- & virüsü vaka sayısı açıklandı! & Koca açkladı! 11Nisan Türkiye'de \\
Koronavirüs (coronavirüs) & & $\begin{array}{l}\text { corona virüsü ölü ve vaka sayısı } \\
\text { kaç oldu? Koronavirüsü canlı } \\
\text { Türkiye son durum vaka ve }\end{array}$ \\
ölüm sayısı haritası & & harita \\
\hline
\end{tabular}


Tablo 4: 25 Kasım 2020 Pozitif Vakaların Tamamının İlan Edildiği Gün

\begin{tabular}{|l|l|l|}
\hline \multicolumn{1}{|c|}{ Hürriyet Haber Sitesi } & \multicolumn{1}{|c|}{ Sabah Haber Sitesi } & \multicolumn{1}{c|}{ Sözcü Haber Sitesi } \\
\hline Son dakika: Fahrettin Koca o & Bakan Koca SON DAKIKA & Corona verileri açılandı! İşte \\
illere dikkat çekti ve günlük & açıladı! 25 Kasım korona & 25 Kasım tablosu \\
vaka sayısını açıladı.. 28 bin & tablosu! Türkiye'de corona & \\
351 yeni koronavirüs vakası.. & virüsü vaka ve ölü sayısı kaç & \\
& oldu? & \\
\hline
\end{tabular}

Başlıklar ile ilgili tematik değerlendirme yapıldığında, Sağlık Bakanı Fahrettin Koca kaynaklı açıklamalara genelde yer verildiği başlık öznesi olarak ise 9 başlığın yedisinde özne olarak yer aldığı görülmektedir.

11 Mart 2020 tarihli haberlerde, Türkiye'de ilk vakanın görülmesi korku ve endişe üzerinden verilmemekle birlikte sadece pandemi ile ilgili ilk vakanın görüldüğü ön planda tutulmaktadır. Küresel salgın ile ilgili biriken bir ardalanın da etkisi ile vaka üzerinden durumun bireylerin de literatürüne giren "pozitif", "pozitif vaka" ya da "ilk kez virüs tespit edildi" şeklinde verildiği görülmektedir.

Pandeminin Türkiye'de ilk dalgasının zirve yaptığ gün olan 11 Nisan 2020 tarihinde verilen haberlere bakıldığında; Sağlık Bakanlığı'nın il il açıkladığı tablolar üzerinden ölüm ve vaka sayısına odaklanıldığı görülmekte, vakalarda en yüksek rakamlara ulaşıldığına dair bilgi yer almamaktadır. Sadece ilk iki ay içerisinde en yüksek rakama ulaşılması ve bunun verilmemesi pandemi ile ilgili normalleşme sürecinin de başladığını, haberi yapanların vaka ve ölüm sayılarına çok ilgi göstermediğini göstermektedir.

Vaka sayılarının bir anda binlerden onbinlere çıktığı gün olan ve Bakan Koca tarafından ilan edilen 25 Kasım 2020 tarihindeki haberlere bakıldığında ise; 28 bin 351 olan vaka sayısının haber başlığında sadece hürriyet com tr tarafından verildiği, sözcü com tr ve sabah com tr tarafından verilmediği görülmektedir. Aynı zamanda hürriyet com tr vaka artışında bazı illere dikkat çekilmesi gerektiği ile ilgili Bakan Koca'nın açıklamalarını başlığa çekerken, sabah com tr "25 Kasım korona tablosu” diyerek genelleme yapmakta, sözcü com tr ise genellemeyi daha da genişleterek "corona verileri açıklandı" şeklinde başlık kullanmaktadır.

Türkçe "korona" şeklinde yazılması gereken kelime bazen "korona" bazen de "corona" şeklinde yazılmaktadır. Örneklemler üzerinden değerlendirildiğinde üç haber sitesinde de yanlış kullanım yoğunluğu dikkat çekmektedir. Hatta aynı haber başlığında bütün haber siteleri farklı tarihlerde hem "korona" hem de "corona" kelimelerini aynı anda kullanmışlardır. 


\subsubsection{Haber Girişi/Spotlar}

Tablo 5: 11 Mart 2020 İlk Vakanın Görüldüğü Gün

\begin{tabular}{|c|c|c|}
\hline Hürriyet Haber Sitesi & Sabah Haber Sitesi & Sözcü Haber Sitesi \\
\hline $\begin{array}{l}\text { Sağlık Bakanı Fahrettin Koca, } \\
\text { corona virüsü ile ilgili son dakika } \\
\text { açılamalarda bulundu. Bakan } \\
\text { Koca, "Bir vatandaşımızın test } \\
\text { sonucu pozitif çıtı" ifadelerini } \\
\text { kullandı. }\end{array}$ & $\begin{array}{l}\text { Dünya genelinde birçok ülkeye } \\
\text { yayılan koronavirüsü hakkında son } \\
\text { dakika açklaması geldi! } \\
\text { Bakan Koca "Bir vatandaşımızın } \\
\text { koronavirüs test sonucu pozitif } \\
\text { çıktı" dedi. İşte son dakika } \\
\text { gelişmesinden tüm detaylar... }\end{array}$ & $\begin{array}{l}\text { Sağlık Bakanı Fahrettin Koca, gece } \\
\text { yarısı yaptığı açılamada, } \\
\text { Türkiye'de ilk Corona virüsü } \\
\text { vakasını açıkladı. Bakan Koca, } \\
\text { "Corona virüsü şüphesi olan } \\
\text { vatandaşımızın test sonucu pozitif } \\
\text { çıktı. Hastanın virüsü Avrupa'dan } \\
\text { aldığı tespit edilmiştir." dedi. }\end{array}$ \\
\hline
\end{tabular}

Tablo 6: 11 Nisan 2020 İlk Dalganın Zirve Yaptığı Gün

\begin{tabular}{|c|c|c|}
\hline Hürriyet Haber Sitesi & Sabah Haber Sitesi & Sözcü Haber Sitesi \\
\hline $\begin{array}{l}\text {...Her gün illere ve ülke genelinde } \\
\text { corona virüs ölüm ve hasta } \\
\text { sayılarını paylaşan Bakanlık, aynı } \\
\text { zamanda corona virüs belirtiler ve } \\
\text { corona virüsten nasıl korunmamız } \\
\text { gerektiği ile ilgili de bilinmesi } \\
\text { gerekenleri de yayınlıyor. Sağlık } \\
\text { Bakanı Fahrettin Koca yaptığı son } \\
\text { durum açıklamasıyla, illere göre } \\
\text { corona yoğunluk hartasını } \\
\text { duyurdu... . ...Türkiye corona } \\
\text { virüs yoğunluk haritasına göre } 11 \\
\text { Nisan Cumartesi günü covid } 19 \\
\text { gov tr internet sitesinden } \\
\text { yayınlanan bilgilere göre ise } \\
\text { Türkiye'de bugünkü test sayısı } 33 \\
\text { bin } 170, \text { yeni vaka sayısı } 5 \text { bin } 138 \\
\text { oldu. Cuma günü toplanan Bilim } \\
\text { Kurulu Toplantısı'nı ardından } \\
\text { Koca yaptığ1 yeni açıklamada, } \\
\text { “Bugünkü iyileşen hasta sayısı } 281 \text {, } \\
\text { toplam iyileşen hasta sayısı } 2 \text { bin } \\
423 \text { oldu." dedi.... }\end{array}$ & $\begin{array}{l}\text { Son dakika haberi... } \\
\begin{array}{l}\text { Bakanı } \\
\text { Fahrettin }\end{array} \text { Koğlıc } \\
\text { coronavirüs vaka ve ölü } \\
\text { sayılarını duyurdu. Bakan } \\
\text { Koca, her gün gerek sosyal } \\
\text { medya hesabından gerek canlı } \\
\text { yayında Türkiye'deki corona } \\
\text { virüsü vaka sayısı, ölü sayısı, } \\
\text { entübe hasta sayısı ve iyileşen } \\
\text { hasta sayısını duyuruyor. } 11 \\
\text { Nisan Türkiye'de corona virüsü } \\
\text { vaka ve ölü sayısı kaç oldu?.... } \\
\text {...Bakan Koca'nın son dakika } \\
\text { açıklamasına göre 11 Nisan } \\
\text { 2020 tarihine ait sayılar şöyle; } \\
\text { test sayısı 33.170, vaka sayısı } \\
5138 \text { ölü sayısı } 95 . \text { İşte } \\
\text { Türkiye'deki corona virüsünde } \\
\text { son dakika bilgileri }\end{array}$ & $\begin{array}{l}\text { Açıklanan yeni verilere göre, } \\
\text { Türkiye'de son } 24 \text { saat içinde } 95 \\
\text { can kaybı yaşandı, } 5 \text { bin } 138 \\
\text { yeni vaka tespit edildi. } \\
\text { Toplamda ise Türkiye'de } 52 \text { bin } \\
167 \text { corona vakası bulunurken } \\
\text { bin } 101 \text { can kaybı yaşandı. }\end{array}$ \\
\hline
\end{tabular}


Tablo 7: 25 Kasım 2020 Pozitif Vakaların Tamamının İlan Edildiği Gün

\begin{tabular}{|c|c|c|}
\hline Hürriyet Haber Sitesi & Sabah Haber Sitesi & Sözcü Haber Sitesi \\
\hline 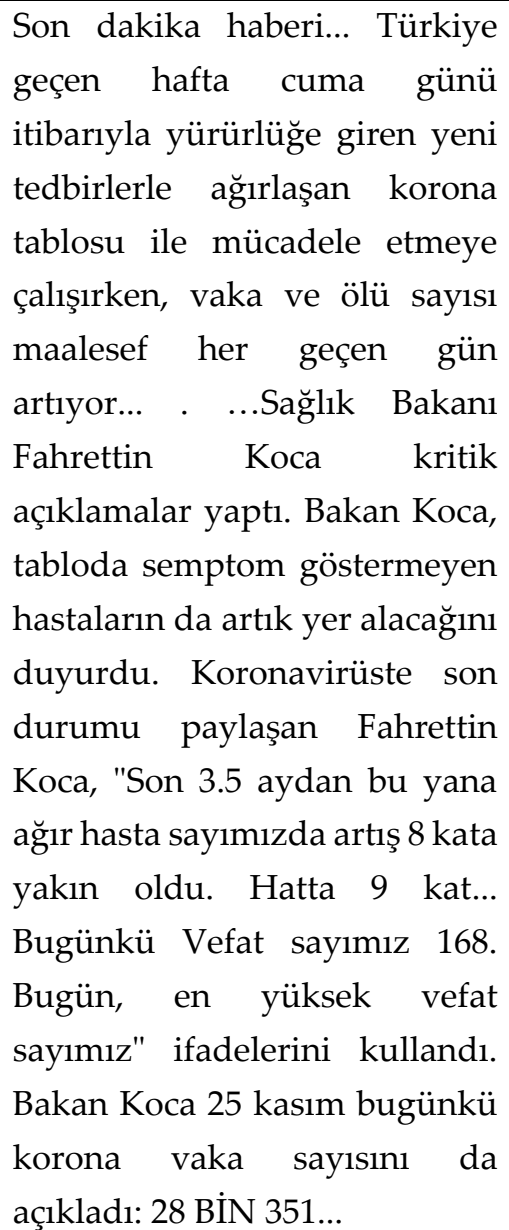 & 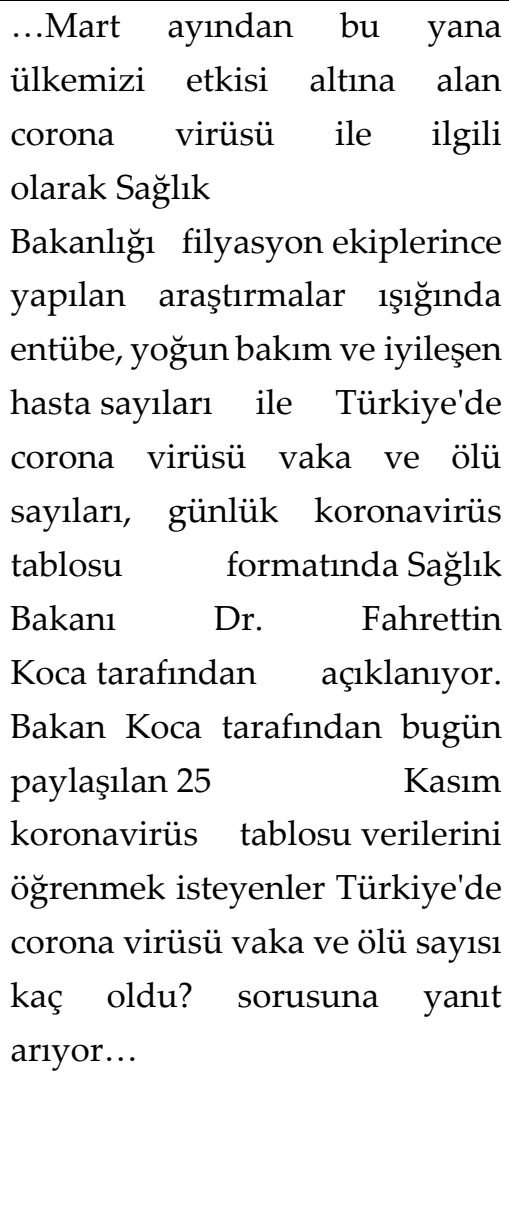 & $\begin{array}{l}\text { Sağlık Bakanlığı'nın açıkladığı } \\
25 \text { Kasım Çarşamba gününün } \\
\text { corona tablosuna göre son } 24 \\
\text { saatte } 168 \text { kişi hayatını } \\
\text { kaybederken } 6 \text { bin } 814 \text { yeni } \\
\text { hasta tespit edildi. Bilim Kurulu } \\
\text { toplantısı sonrası açılama } \\
\text { yapan Bakan Koca, yeni hasta } \\
\text { sayısıyla birlikte bugün } \\
\text { Türkiye'de toplam } 28 \text { bin } 351 \\
\text { vakanın tespit edildiğini } \\
\text { duyurdu. }\end{array}$ \\
\hline
\end{tabular}

Haber girişleri-spotlar ile ilgili değerlendirmelerde yaşanan süreç ile özdeşleşen isim olan Bakan Koca'nın tam 17 kez haber kaynağı ya da öznesi olarak kullanıldığı görülmektedir. Bu sayı Koca'nın pandemi sürecinde en çok gündemde olan isim olmasının bir göstergesidir. Ayrıca Sağlık Bakanlığı da haber başlıklarından farklı olarak giriş ve spotlarda 5 kez haber öznesi ya da kaynağı olarak kullanılmıştır. Süreç devam ederken her akşam çoğunlukla kameralar karşısında son zamanlarda ise sosyal paylaşım platformu Twitter'dan açılamaları ile Koca, akşam saatlerinde Türkiye'de son dakika haberlerinin öznesi haline gelmiştir. Son zamanlarda yapılan araştırmalar* bu tarz haberlere olan ilginin azaldığını göstermektedir. Vaka, test sayısı, vefat eden, aktif hasta sayısı, zatürre oranı vb. kelimelerin sürekli kullanılması ve aynı haber ve kelime kalıpları ekseninde verilmesi okuyucu ya da kullanıcı üzerinde olumsuz bir etki yaratmakta bu da habere olan ilginin azalmasına sebep olmaktadır.

11 Mart 2020'de haber girişleri ve spot cümlelere bakıldığında haber girişlerinin ele alındığ1 sonraki günlere nazaran oldukça az ve sığ bilgiler içerdiği görülmektedir. Pandeminin

\footnotetext{
* Axios-Newswhip 2020 araştırma sonuçlarına ayrıntılı olarak bakabilirsiniz.
} 


\section{AJIT-e Bilişim Teknolojileri Online Dergisi \\ Academic Journal of Information Tecnology \\ 2021 Spring/Bahar - Cilt/Vol: 12 - Sayı/Issue: 45 \\ doi) 10.5824/ajite.2021.02.003.x}

yeni bir etki alanı oluşturduğu düşünüldüğünde bunun normal olduğunu söylemek mümkündür. Haber başlıklarında görülen korku ve endişe haber spot ya da girişlerinde mevcut değildir. Üç haber sitesi de burada daha çok bir pozitif vaka olduğunu, cinsiyetinin erkek olduğunu ve virüsün ülkeye girişinin Avrupa kaynaklı olduğunu bildirmektedir.

11 Nisan 2020 yani ilk dalganın en yüksek vaka sayısına ulaşıldığı güne bakıldığında ise daha ayrıntılı verilen ve uzun cümleler ile karşılaşıldığı görülmektedir. Özellikle Hürriyet ve Sabah haber sitelerinde haber giriş ve spotlarının günce (günlük) gibi verildiği görülmekte, cümle kalıplarında bozuklukların olduğu, anlaşılmayan ve uzun cümleler ile virüs ve salgın ile ilgili toplama bilgilerin "derleme haber" ya da galerilerle verildiği görülmektedir. Bu iki örneğin aksine Sözcü haber sitesinin ise bu iki örneğe nazaran yalın ve anlaşılır bir dil kullanarak haber yazma ilkelerine yazım kuralları çerçevesinde daha çok dikkat ettiği görülmektedir.

Haber girişlerinde Türkiye' deki vaka sayıları ayrıntılı olarak verilmekte, 11 Nisan 2020 itibarı ile en çok can kaybının yaşandığı gün olması nedeni ile Sabah ve Sözcü'de 95 can kaybının olduğu ifade edilmekte, Hürriyet'te ise bu rakam verilmemekle beraber her geçen gün ölü ve vaka sayısının artışına vurgu yapılmaktadır. 11 Nisan 2020'ye kadar toplam can kaybı sayısının ise sadece Sözcü'de yer aldığ1 görülmektedir. Günlük 33 bin 170 test yapıldığını Hürriyet ve Sabah verirken, Sözcü'nün test sayısını vermediği görülmektedir. Yapılan testler sonrası pozitif olan 5 bin 138 yeni vaka sayısının ise araştırma kapsamında değerlendirilen bütün haber siteleri tarafından verildiği görülmektedir. Özetle 11 Nisan 2020 haber giriş ve spotlarına bakıldığında Hürriyet ve Sabah'ın ayrıntıya girdiği ve anlamdan uzaklaştığı görülürken, Sözcü'nün daha basit bir dille önemli olan veriler üzerinde odaklandığı görülmektedir.

Pozitif vakalarının tamamının ilan edildiği ve araştırmamızın da üçüncü ve son günü olan 25 Kasım 2020 verilerine bakıldığında; 11 Nisan 2020 üzerinden yapılan birçok tespit ve değerlendirmenin aynı hatta yapılan hataların daha da artarak devam ettiği görülmektedir.

Hürriyet haber sitesi haber giriş ve spotlarında korona tablosunun gün geçtikçe ağırlaştı̆̆ını, vaka ve ölü sayılarının arttığını (maalesef takısı ile vermekte), karantina süreci ile ilgili yeni kısıtlamalara yenilerinin ekleneceğini belirtmektedir. Ayrıntılı vaka sayısı artık verilmemekle bilirlikte, Bakan Koca'nın salgında hastalık oranın 9 kat arttığı belirtilerek, son veri olarak ise 28 BİN 351 (büyük yazı ile vermek tercih edilmiş) yeni pozitif vakanın olduğuna vurgu yapilmaktadir.

Sabah haber sitesi haber giriş ve spotlarında 11 Mart 2020 tarihine yani ilk vakanın Türkiye'de görüldüğü güne vurgu yaparak haber girişi inşa etmiştir. Sabah haber sitesinde dikkati çeken 25 Kasım 2020 tarihinde verilen en yüksek pozitif vaka sayısının verilmemesi, 
ayrıca vaka ve ölü sayılarını ile ilgili tek bir bilginin dahi haber giriş ve spotunda yer almamasıdır. Bu durum habercilik ilkelerinin site tarafından etkili kullanılmadığını ya da kullanılmak istenmediğini göstermektedir. Sağlık çalışanlarından oluşan filyasyon ekipleri tarafından yapılan çalışmalar sonucu "entübe”, "yoğun bakım”, “iyileşen, vaka ve ölü sayısı" gibi bilgilerin Bakan Koca tarafından aktarıldığını belirten haberde, vaka sayısındaki rekor artışın hiçbir şekilde haber giriş ve spotunda yer almadığı görülmektedir.

Sözcü haber sitesi ise diğer iki haber sitesinden farklı olarak yalın bir dil tercih edip ters piramit kuralını kullanarak, "vaka", "hayatını kaybedenler", "yeni hasta sayılarına" odaklanmıştır. Hürriyet haber sitesinde olduğu gibi haber girişinin son kısmında ise 28 bin 351 olan ve ilk kez kamuoyuna açıklanan vaka sayısı bilgisinin verildiği görülmektedir. Haber yazım kuralları dikkate alındığında en etkili ve anlaşılır tekniğin bu örneklemde Sözcü haber sitesinin kullandığını göstermektedir.

Son olarak Türkçe "korona”, İngilizce "corona” olan pandeminin ismi ile ilgili kelime kullanımında 11 Mart 2020 haberlerine kıyasla 11 Nisan 2020 ve 25 Kasım 2020 haberlerinde ikilem devam etmekte ve iki kelime de aynı cümlelerde kullanılarak hata yapılmaya devam edilmektedir. Ayrıca çok uzun ve anlamdan uzaklaşan cümleler kuran Hürriyet ve Sabah haber sitelerinde uzun cümleler nedeni ile hem noktalama işaretlerinde hem de anlatım bozukluğu, cümle yapısındaki düşüklük gibi çok önemli dil bilgisi sorunlarının olduğu görülmektedir. Üç nokta gibi noktalama işaretlerinin Hürriyet ve Sabah haberlerinde çok kullanıldığı da dikkati çekmektedir.

\subsubsection{Fotoğraf ve Görseller}

11 Mart 2020 tarihinde, üç haber sitesi de sadece Bakan Koca'nın fotoğrafını kullanmış, korona virüs ile ilgili herhangi bir tablo, grafik, resim vb. kullanılmamıştır.

11 Nisan 2020 tarihinde, üç haber sitesinde yine benzer bir yaklaşım söz konusudur. Üç haber örneğinde de Bakan Koca'nın görseli ve “Türkiye Günlük Korona Pandemi Tablosu” verilmiştir.

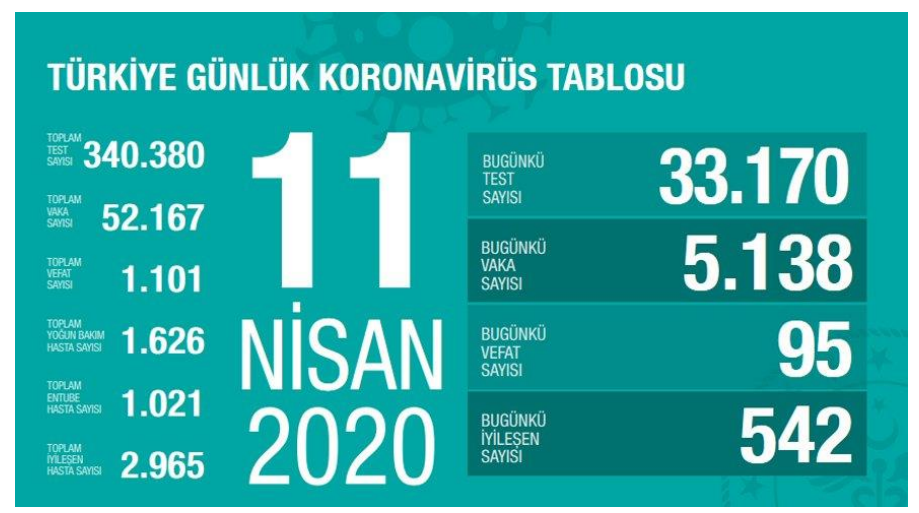

Görsel 1: Günlük Vaka Analiz Tablosu (Kaynak: Sağlık Bakanlığı Web Sitesi) 


\section{AJIT-e Bilişim Teknolojileri Online Dergisi \\ Academic Journal of Information Tecnology}

2021 Spring/Bahar - Cilt/Vol: 12 - Sayı/Issue: 45

doi) 10.5824/ajite.2021.02.003.x

25 Kasım 2020 tarihinde ise haber siteleri açısından farklılıkların olduğu görülmektedir. Hürriyet haber sitesi verdiği haberde sadece Bakan Koca'nın video haberine yer vermekte ve bu video haberinde metin olarak ara başlıklar ile uzun bir şekilde aktarımını yapmaktadir.

Görsel ve fotoğraf konusunda 25 Kasım haber örneğinde en ayrıntılı aktarımı yapan Sabah haber sitesidir. 25 Kasım 2020 tarihli haberde Sabah internet sitesi, sağlık çalışanı merkezli 2 fotoğraf (bunlardan 1.cisi sedyede hasta taşıyan sağlık çalışanları, 2.si ise aşı yapan sağlık çalışanı görselidir) kullanılmıştır.
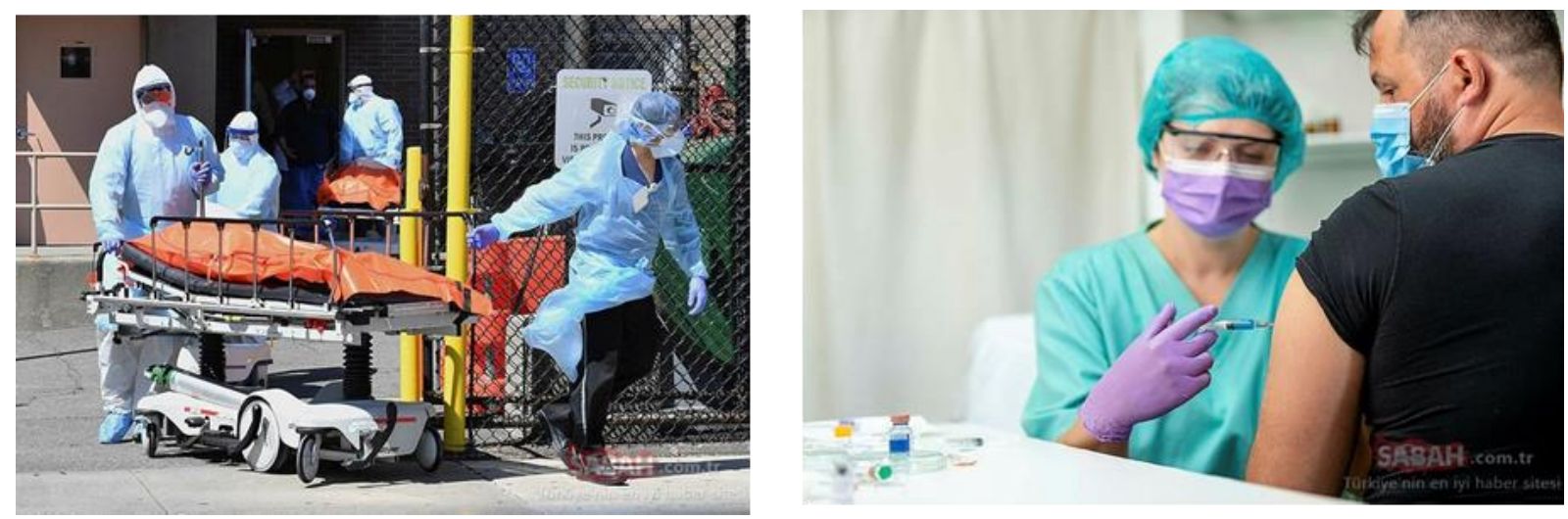

Görsel 2-3: Sağlık Çalışanı Görseli (Kaynak: sabah.com.tr)

Toplu taşıma araçlarından 3 fotoğraf (1. fotoğraf belediye otobüsü, 2. ve 3. fotoğraf ise şehir hatları vapurundan kareler) kullanmıştır. Ayrıca sokaklardaki hareketlilik ve maske kullanımı ile ilgili görseller haber ile birlikte verilmiştir.
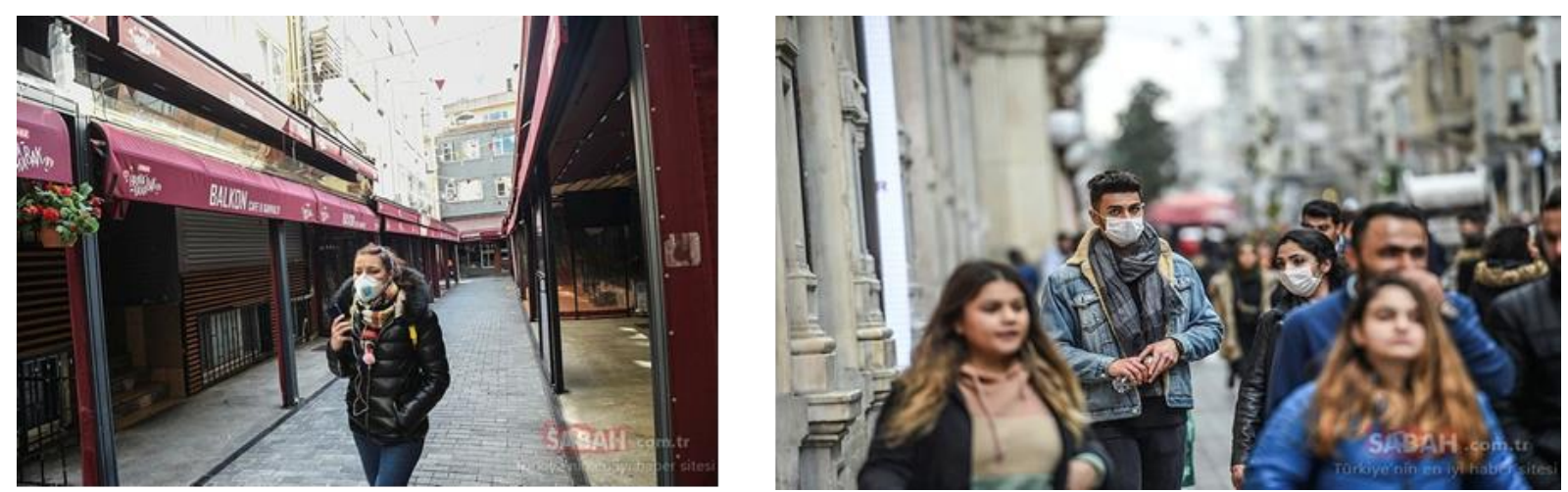

Görsel 4-5: Sokaktaki Hareketlilik ve Maske Kullanımı ile İlgili Görsel (Kaynak: sabah.com.tr)

Sözcü haber sitesi de Sabah haber sitesine benzer bir yaklaşımla haber inşasında görsel ve fotoğraflara yer vermiştir. Sitede 25 Kasım 2020 tarihli haberde yoğun bakımda yatan bir hasta ve ona yardım eden bir sağlık çalışanı fotoğrafı ve iki tane günlük koronavirüs tablosu verilmiştir. 


\section{SONUÇ VE DEĞERLENDİRME}

Dijk'ın söylem analizinde internet haberlerinde ele alınan söylemin makro yap1 üzerinden değerlendirildiği bu çalışmada elde edilen veriler; online gazeteciliğin gazetecilik haber yazım ilkeleri ve teknikleri açısından ciddi sorunlar barındırdığını göstermektedir.

Öncelikle geleneksel medyada yer alan haberlere kıyasla online mecrada verilen haberlerin gazetede olduğu gibi belirli bir sütun ya da ölçü üzerinden verilme zorunluluğu olmadığı için siber uzamsal alanda gereksiz bir şekilde çok uzun yazıldığg görülmektedir. Bu noktada söylem analizi yapan ya da dil bilgisi kurallarını dikkate alan birçok araştırmacı ya da bilim insanının da üzerinde durduğu bir sorunla karşılaşıldığı görülmektedir. Buradaki asıl sorun anlamdan uzaklaşan bu uzun cümlelerin vermek istediği mesajın geri plana itildiği sonucunu doğurması bunun da gazeteciliğin temel kuralı olan "bilgilendirme"den hızla uzaklaşıldığını göstermesidir. Yapılan incelemede uzun uzadıya kurulan cümleler sadece bir sorun değildir, ayrıca cümle yapılarında da anlamsız birçok kullanım, imla ve yazım yanlışlarının olduğu tespit edilmiştir. Örneğin İngilizce olan "corona" kelimesi "korona" ile sürekli karıştırılmış ve hatta aynı cümlede aynı anlama gelen bu kelimeler birlikte kullanılmıştır.

Başlıkların kullanımında Hürriyet ve Sabah haberlerinde gereksiz ve uzun olan birçok ayrıntı mevcut iken Sözcü haberlerinin daha yalın verildiği ve cümle yapısı ya da inşasına daha çok dikkat edildiği tespit edilmiştir. Haber girişlerinde de aynı durum devam etmiş ve hayatını kaybeden ya da hasta olan bireylerin sadece rakamlara dönüştüğü görülmüştür. Hürriyet ve Sabah çok uzun ve toparlama haber mantığı ile pandemi hakkında genel bilgi verme eğiliminde iken Sözcü daha çok o gün olanlar üzerinden yine başlıklarda kullandığ sade ve yalın dili tercih etmiştir.

İlk vakanın göründüğü günden en çok vaka sayısının açılklandığı güne kadar olan ve ele alınan üç haber sitesi örneklemleri üzerinden, zamanla aktarılan haberlerin korku ve endişeden uzaklaşarak sanki günlük takvim bilgisi veriliyormuş gibi bir yaklaşıma doğru gittiği görülmektedir. Bu durum zamanla çalışmada da ifade edildiği gibi hem sürecin hep "aynılık" üzerine inşa edildiğinin hem de her gün aynı haber akışına maruz kalan bireyin artık pandemi ile ilgili bilgilere ilgisinin azaldığının bir tezahürüdür ve haber örneklerine bile bu yansımıştır. Örneğin pozitif vakaların tamamının ilan edildiği gün olan 25 Kasım 2020 verilerine bakıldığında bir an da binlerde olan vaka sayısının onbinlere (28 binlere) dayanmasına rağmen bu bilgi Sabah haber sitesinde ele alınan örneklemin çok uzun olmasına rağmen giriş cümlesinde yer almamaktadır. Hürriyet ve Sözcü'de ise son cümlenin bitmesine yakın verilmektedir. Bu durum sadece haberi okuyanların değil haberi yapanların da artık tek düze bir anlayışa göre haber kurallarını hiçe sayarak hareket ettiğini göstermektedir. Zira pozitif vakaların tamamının Sağlık Bakanlığı tarafından açıklanması yalnızca Türkiye'de değil aynı zamanda dünya gündeminde de ilk sıralarda gündeme gelen çok önemli bir gelişmedir. 
Hem başlıklarda hem de haber girişlerinde/spotlarda ana kahraman Sağlık Bakanı Koca olmuştur. Her gün pandemi özelinde neredeyse tek haber kaynağı olması nedeni ile Bakan Koca araştırma kapsamında olan bütün haber metinlerinde ana kahraman ya da haberin öznesi olarak geçmektedir.

Tematik yapının öğelerinden bir diğer önemli konu başlı̆̆ı ise haberlerde kullanılan fotoğraf, infografik ya da tablolardır. Çalışmada pandeminin ilk zamanlarında Bakan Koca'nın fotoğrafı bütün örneklemlerde kullanılmıştır. Sonrasında bakanlığın hergün açıkladığ1 günlük korona tablosu yine online haberlerde vaz geçilmez görsel olarak yer almıştır. Kullanılan görsellere dair son olarak pandemide ikinci dalganın başlaması ile birlikte hasta, sağlık çalışanı, iğne yaptıran hasta, toplu ulaşım ile ilgili kalabalık insan görüntülerinin daha yoğun kullanıldığı görülmektedir.

Online gazetecilik ortamında haberin inşası ile ilgili sıkıntıların pandemi ile ilgili haberler ekseninde değerlendirildiği bu çalışma ile gerçek olan ile dijital olanın birleşmesinden ortaya çıkan "fijital" kavram ekseninde birçok bilgi ya da enformasyonun silikleştiği ya da anlamından uzaklaştığı yaptığımız çalışmada elde edilen bulgulardan da görülmektedir. Pandemi sürecinde günlük vakaların ele alındığı haberlerde aktarılan bilgilerin zamanla havada uçuşan rakamlardan başkaca bir şey olmadığı tespit edilmekte bu da zamanla daha da anlamsız hale gelen haber metin inşalarının zamanla daha da artması anlamına gelmektedir. Bu nedenle söylem analizleri ile ele alınan çalışmaların dikkatli bir şekilde değerlendirilerek habercilik kural ve felsefesinin online ortamlarda yaygınlaşması ile ilgili çalışmaların yapılması ve bu konuda önemli yapısal adımların atılması gerekmektedir.

\section{KAYNAKÇA}

Axios, (2020). COVID cases are spiking, but our attention isn't, https://www.axios.com /covid-attentionsocial-media-661ecdc3-0669-459a-a491-ed7fb069ab29.html?utm_source=ne wsletter\&utm_medium=email\&utm_campaign=newsletter_axiosmediatrends\&stream=top, Erişim Tarihi: 22.12.2020.

Barker, C. and Galasinski, D. (2001). Cultural studies and discourse analysis: a dialogue on lnaguage and identity. London: Sage

Çalışkan, N. (2020). 'Yeni Normali'n de Yeni Normali: 'Fijital'in Zamanı Asıl Şimdi., https://iabtr.org/UploadFiles/Reports/iab_Makale_Fijital8102020153432.pdf, Erişim Tarihi: 22.12.2020.

Çelik, H. ve Ekşi, H. (2013). Söylem Analizi. Marmara University Atatürk Education Faculty Journal of Educational Sciences, 27 (27), 99-117. Retrieved from: https://dergipark.org.tr /tr/pub/maruaebd/issue/365/2517. 
Elliot, R. (1996). Discourse analysis: exploring action, function and conflict in social texts. Marketing Intelligence \& Planning. 14, 6, p.65.

Hürriyet, (Mart 2020)._https://www.hurriyet.com.tr/video/bakan-koca-bir-vatandasimizin-test-sonucupozitif-cikti-41465998, Erişim Tarihi: 12.12.2020.

Hürriyet, (Nisan 2020). https://www.hurriyet.com.tr/galeri-saglik-bakanligi-corona-virusu-il-iltablosu-11-nisan-koronavirus-coronavirus-turkiye-son-durum-vaka-ve-olum-sayisi-haritasi41489036, Erişim Tarihi: 19.12.2020.

Hürriyet, (Kasım 2020). https://www.hurriyet.com.tr/gundem/son-dakika-fahrettin-koca-gunluk-vakasayisini-acikladi-son-24-saatte-28-bin-351-yeni-vaka-41672072, Erişim Tarihi: 26.12.2020.

Mutlu, E. (2012). İletişim Sözlü̆̆̈̈. Ankara: Sofos-Kıta Basın Dağıtım Yayıncılık.

Parker, I. (1990). Real thing: discourse, context and practice. Philosophical Psychology, 3 (2), 189-204.

Parker, I. (2002). Discourse analysis. P. Banister., E. Burman., I. Parker., M.Taylor., C. Tindal. In. Qualitative Methods in Psychology: A Research Guide. (pp.92-108). Buckingham: Open University Press

Potter, J., and Wetherell, M. (1987). Discourse and social psychology: Beyond attitudes and behaviour, London: Sage.

Sabah, (Mart 2020). https://www.sabah.com.tr/gundem/2020/03/10/bakan-koca-aciklama-yapacak, Erişim Tarihi: 12.12.2020.

Sabah, (Nisan 2020). https://www.sabah.com.tr/gundem/2020/04/11/son-dakika-bakan-koca-guncelcoronavirus-vaka-ve-olu-sayisini-acikladi, Erişim Tarihi: 19.12.2020.

Sabah, (Kasım 2020). https://www.sabah.com.tr/galeri/turkiye/bakan-koca-son-dakika-acikladi-25kasim-korona-tablosu-turkiyede-corona-virusu-vaka-ve-olu-sayisi-kac-oldu-saglik-bakanligigunluk-son-durum-tablosu/12, Erişim Tarihi: 26.12.2020.

Sözcü, (Mart 2020). https://www.sozcu.com.tr/2020/gundem/son-dakika-saglik-bakani-kocadan-geceyarisi-corona-virusu-aciklamasi-5672490/, Erişim Tarihi: 12.12.2020.

Sözcü, (Nisan 2020). https://www.sozcu.com.tr/2020/gundem/son-dakika-turkiyedeki-son-coronavirusu-vaka-sayisi-aciklandi-11-04-2020-5741929/, Erişim Tarihi: 19.12.2020.

Sözcü, (Kasım 2020). https://www.sozcu.com.tr/2020/gundem/son-dakika-corona-verileri-aciklandiiste-25-kasim-tablosu-6141074/, Erişim Tarihi: 26.12.2020.

Van, Dijk, T. A. (2003). Critical discourse analysis. D.Schiffrin., D. Tannen, \& E., H. Hamilton (Ed.), In The Handbook of Discourse Analysis. (352-372). Oxford: Blakwell Publishing

Van, Dijk, T.A. (2009). News, Discourse, and Ideology, In The Handbook Of Journalısm Studies, Editors: Karin Wahl-Jorgensen and Thomas Hanitzsch, pp:191-204.

We Are Social, (2020). Digital In 2020, https://wearesocial.com/blog/2020/01/digital-2020-3-8-billionpeople-use-social-media, Erişim Tarihi: 08.03.2021. 
AJIT-e Bilişim Teknolojileri Online Dergisi

Academic Journal of Information Tecnology

2021 Spring/Bahar - Cilt/Vol: 12 - Sayı/Issue: 45

doi) 10.5824/ajite.2021.02.003.x

Webrazzi, (2020). Türkiye'nin en çok ziyaret edilen 20 web sitesi, https://webrazzi.com /2020/05/12/turkiyenin-en-cok-ziyaret-edilen-20-web-sitesi/, Erişim Tarihi: 15.11.2020.

Wodak, R. and Meyer, M. (2002). Methods of critical discourse analysis. London: Sage Publications.

Wood, L., A. and Kroger, R., O. (2000). Doing discourse analysis: methods for studying action in talk and text. Lodan: Sage Publications. 